\title{
In-vitro antibacterial effects of methanolic extract of peppermint (Mentha Piperita Lamiaceae) on standard Staphylococcus aureus, Bacillus cereus, Escherichia coli and Pseudomonas aeruginosa strain
}

\author{
Samira Mahmoudi ${ }^{1}$, Rozita Nasiri ${ }^{2}$, Abolfazl Jafari Sales ${ }^{3 *}$ \\ 1. Department of Microbial Biotechnology, School of Biological Sciences, Islamic Azad University Tehran North \\ Branch, Tehran, Iran \\ 2. Iran National Elite Foundation, Tehran, Iran. \\ 3. Department of Microbiology School of Basic Sciences, Kazerun Branch, Islamic Azad University, Kazerun, Iran.
}

Article Type:
Original Article

Article History:

Received: 10 May 2019

Revised: 11 Jul 2019

Accepted: 10 Sep 2019

*Correspondence:

Abolfazl Jafari-Sales, Department of Microbiology, School of Basic Sciences, Kazerun Branch, Islamic Azad University, Kazerun, Iran. A.jafari_1392@yahoo.com

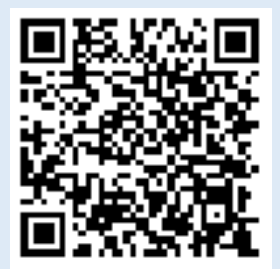

\begin{abstract}
Background and objectives: Microbial resistance to antibiotics is one of the most common problems in the health care system. Therefore, many efforts have been performed to find new compounds as antimicrobial compounds. This study carried out to investigate the in-vitro antibacterial effect of methanolic extract of peppermint on standard Staphylococcus aureus, Bacillus cereus, Escherichia coli and Pseudomonas aeruginosa strains.

Methods: In this experimental laboratory study, after collecting and performing pharmacognosy evaluations, methanolic extract of the peppermint plant was prepared and its antimicrobial effects on several bacteria were determined at concentrations of 20 to $400 \mathrm{mg} / \mathrm{ml}$ using the agar well diffusion method, minimum inhibitory concentration (MIC), minimum bactericidal concentration (MBC) methods. The test was repeated five times for each bacterium and the collected data were analyzed using SPSS software.

Results: The methanolic extract of peppermint had antimicrobial effects against standard strains of Staphylococcus aureus, Bacillus cereus, Escherichia coli and Pseudomonas aeruginosa. The highest effect was observed in $S$. aureus and the least in P. aeruginosa. MIC and MBC of methanol extract on S. aureus, B. cereus, E. coli, and P. aeruginosa were $6.5-15.5,15.5-25,50-100$, and $100-200 \mathrm{mg} / \mathrm{ml}$, respectively.

Conclusion: The results of this study showed that peppermint extract can be considered as an antibacterial medicinal herb and that if the concentration of the extract increases, its antibacterial properties will also increase. Thus, it can be used as an alternative to the usual chemical drugs in the treatment of infections after evaluating their effects in vitro.
\end{abstract}

Keywords: Antibacterial effect, Methanolic extract, Peppermint, In vitro.

Copyright $@$ 2018, Jorjani Biomedicine Journal has published this work as an open access article under the terms of the Creative Commons Attribution License (http://creativecommons.org/licenses/by-nc/4.0/) which permits noncommercial uses of the work while it is properly cited. 


\section{Introduction}

The resistance of microorganisms to antibiotics raises problems that have become one of the major concerns of human society and the health care system (1). With the emergence of antibiotic-resistant, the efficacy of existing drugs has decreased and this has increasingly enhanced the failure of antimicrobial therapies (2). Besides, the widespread use of industrial-origin drugs as well as improper use of these drugs can cause many side effects, sometimes resulting in more serious toxic effects than the disease itself (3). One way to prevent the emergence of antibiotic resistance is to use compounds that work similar to antimicrobial drugs but differ from existing industrial sources $(4,5)$. In fact, due to the increasing incidence of antibiotic resistance, there is a pressing need for new antibacterial drugs, and of the potential sources, such as plants (6). The use of medicinal herbs has been one of the earliest human achievements to treat most diseases in different countries, because the plants make compounds that are related to the antimicrobial properties, including alkaloids, flavonoids, isoflavonoids, tannins, glycosides, and phenolic compounds. In other words, secondary metabolites in plants have antimicrobial properties (7). Mentha includes more than 25 species, but the most common species used is Mentha piperita Lamiaceae (Peppermint). It is one of the most popular aromatic plants, which have traditionally been used in folk medicine. Peppermint is a combination of blue mint and ornamental or spicy mint (8). It has dark green and fragrant leaves and grows 60 to $90 \mathrm{~cm}$. Peppermint is a perennial herbaceous plant whose leaves, are elliptic, transverse, serrate, slightly lanceolate, $4-7 \mathrm{~cm}$ long and $2-3 \mathrm{~cm}$ wide. Peppermint has high menthol content and its oil also contains menthone and carboxyl esters. For this reason, it seems that it can have antimicrobial properties (9). Today, in different countries of the world, more than one thousand tons of oils are produced from this plant, which shows its importance in different parts of the world. Much research has been done on the medicinal properties of peppermint (10). Hence, the objective of this study was to assess the antimicrobial properties of Mentha piperita Lamiaceae on standard bacteria, including $S$. aureus, $B$. cereus, E. coli and $P$. aeruginosa in vitro.

\section{Materials and Methods}

\section{Preparation of the peppermint plant}

Plant samples were collected from natural areas around Tabriz city, Iran. After collection and transfer, the samples were cleaned and dried in a large, well-ventilated area away from sunlight. First, the samples were completely dried, aerial organs such as stems were wounded, and leaves attached to roots were removed, then they were prepared for grinding.

\section{Extraction of methanol extract}

Soxhlet method was used for extraction so that $60 \mathrm{~g}$ of dried plant powder with $300 \mathrm{ml}$ of methanol as solvent was placed in Soxhlet extractor for 8 hours. The solvent evaporated slowly and was concentrated by using a rotary apparatus at $40^{\circ} \mathrm{C}$. Next, 5\% Dimethyl sulfoxide (DMSO) was used to prepare the extracts. The concentrations of the extracts were $20,30,50$, and $400 \mathrm{mg} / \mathrm{ml}$ for using in Minimum Inhibitory Concentration (MIC) and Disc diffusion experiments. 


\section{Preparing the standard microorganisms}

The microorganisms studied in this study were: Staphylococcus aureus ATCC 25923, Bacillus cereus ATCC 1247, Escherichia coli ATCC 25922, and Pseudomonas aeruginosa ATCC 27853. All strains were prepared from the microbial collection at the University of Tehran. The culture was performed on the Muller Hinton agar medium (Merck, Germany) to obtaining colonies, then, to prepare microbial suspension from fresh culture, 4-5 colonies were transferred to Mueller Hinton Broth medium (Merck, Germany) and microbial turbidity prepared according to McFarland standard tube No. 0.5 $\left(1.5 \times 10^{6} \mathrm{CFU} / \mathrm{ml}\right)$. To reach the bacterial concentration of $1.5 \times 10^{6} \mathrm{CFU} / \mathrm{ml}$, microbial suspension diluted to $0.5 \mathrm{McFarland}$ tube equivalents to 0.01 and next, it was checked by spectrophotometer.

\section{Investigation of the antimicrobial effect of methanol extract}

To investigate the antimicrobial effect of peppermint methanol extract, concentrations of $20,30,50$, and $400 \mathrm{mg} / \mathrm{ml}$ of methanol extract were prepared in 5\% DMSO solventIn this study, the agar well diffusion and dilution test were used to investigate the antimicrobial effect of methanol extract.

\section{Determination of the antimicrobial effect by agar well diffusion}

In the agar well diffusion method, $500 \mu 1$ of the microbial suspension was transferred to the Muller Hinton agar medium and it was cultured by sterile swabs in three directions. Then, wells were made at $6 \mathrm{~mm}$ in diameter and $2.5 \mathrm{~cm}$ apart on the culture medium surface (the bottom of the wells filled with the medium again). Finally, 100 $\mu 1$ of 20, 30, 50, and $400 \mathrm{mg} / \mathrm{ml}$ concentrations of the methanol extract were loaded into each well.
The 5\% DMSO was used as negative control and chloramphenicol was used as a positive control. Plates were then incubated at $37^{\circ} \mathrm{C}$ for $24 \mathrm{~h}$ and microbial cultures were measured for the presence or absence of growth zone in millimeters.

\section{Determination of MIC and MBC}

The minimum inhibitory concentration (MIC) and minimum bactericidal concentration (MBC) of methanol extract were determined by dilution test. In this method, for the determination of MIC, the methanol extract was prepared in serial dilutions of $6.25,12.5$, $25,50,100$, and $200 \mathrm{mg} / \mathrm{ml}$ from Mueller Hinton broth. Then, $1 \mathrm{ml}$ of the active bacterial suspension $\left(1.5 \times 10^{6} \mathrm{CFU} / \mathrm{ml}\right)$ was added to each dilution; positive control (medium containing bacterial and without extract) and negative control (medium without bacterial) were used. Finally, the tubes were incubated at $37^{\circ} \mathrm{C}$ for $24 \mathrm{~h}$. After incubation, the tubes were examined for turbidity due to bacterial growth; and the last dilution in which no turbidity was observed (non-growth) was considered as MIC.

Samples were obtained from all tubes with no growth. Minimum bactericidal concentration (MBC) was determined by plate culture. Plates were incubated for 24 hours at $37^{\circ} \mathrm{C}$; the tube with the lowest concentration of extract that the bacterial growth was visible on its plate was considered as MBC of that substance. Each experiment was repeated 5 times to reduce the error of the experiment. Statistical analysis was performed using SPSS software. ANOVA and Chi-square tests were used to investigate the significant differences in the results. The difference between groups was determined. 


\section{Results}

According to Table 1, the antibacterial activity of methanol extract of peppermint in quantitative and qualitative methods showed that this extract has a significant inhibitory effect on S. aureus and B. cereus bacteria. The inhibitory effect was enhanced by increasing the concentration of methanolic extract. This study proved that the inhibitory effects of peppermint methanolic extract on gram-positive bacteria were significantly higher compared to gram-negative bacteria. MIC and MBC values of methanol extract of peppermint against the tested bacteria revealed that, like the well diffusion method, peppermint extract on gram-positive bacteria has a higher bactericidal effect than gramnegative bacteria (Table 2). These results indicated that there was a significant difference between the tested bacteria in the sensitivity of peppermint ( $p<0.05)$.

Table 1: Mean diameter of non-growth zone of methanolic extract of peppermint against selected bacteria in millimeters (mean \pm standard deviation)

\begin{tabular}{|c|c|c|c|c|r|r|}
\hline Concentration of Extract & 20 & 30 & 50 & 400 & $\begin{array}{r}\text { Negative } \\
\text { control }\end{array}$ & $\begin{array}{r}\text { Positive } \\
\text { control }\end{array}$ \\
\hline Bacteria Strain $(\mathrm{mg} / \mathrm{ml})$ & & & & & & \\
\hline S. aureus & $9.8 \pm 0.83$ & $15.2 \pm 0.83$ & $20.6 \pm 1.15$ & $25.6 \pm 1.14$ & -- & 23 \\
\hline B. cereus & $8.4 \pm 1.14$ & $14.4 \pm 1.14$ & $18.4 \pm 0.57$ & $24.4 \pm 1.14$ & -- & 21 \\
\hline E. coli & 0 & $11 \pm 0.70$ & $15.2 \pm 0.83$ & $19.8 \pm 1.15$ & -- & 25 \\
\hline P. aeruginosa & 0 & 0 & $9.8 \pm 1.30$ & $12.4 \pm 1.67$ & -- & 24 \\
\hline
\end{tabular}

Table 2. MIC and MBC values of methanol extract of peppermint $(\mathrm{mg} / \mathrm{ml})$

\begin{tabular}{|c|c|c|}
\hline Concentration of Extract & MIC & MBC \\
\hline S. aureus & & 12.5 \\
\hline B. cereus & 6.25 & 25 \\
\hline E. coli & 12.5 & 100 \\
\hline P. aeruginosa & 50 & 200 \\
\hline
\end{tabular}

\section{Discussion}

Nowadays, bacteria resistance has enhanced to a variety of antibiotics, therefore, many efforts have been made to obtain and use new compounds. Some of these compounds come from plants. Plants have played an important role in maintaining health and improving the quality of human life for thousands of years (11). Mentha Piperita that is the most popular 
member of this family, commonly known as Peppermint, has long been used as an aromatic and appetizing plant. Medicinal properties of peppermint include antispasmodic, anti-vomiting, and antibloating (12). Peppermint is one of the most widely consumed medicinal plants with an annual consumption of about 7,000 tons worldwide (13). Tylor VE in 1993 introduced peppermint as a rich source of metabolites that have major nutritional uses and have also antispasmodic and antibacterial features (14). Iscan et al. in 2002, found that lipopolysaccharides in the external membrane of gram-negative bacteria are responsible for their higher resistance to antibacterial agents (15). Dorman HJD et al. stated in their studies that some essences such as that of peppermint are highly efficient on E.coli (16). In 2005, Moreira MR et al. surveyed the antimicrobial effects of different plants on various species of E.coli; and the essence of peppermint showed significant antimicrobial effects (17). Antibacterial activity of peppermint oil against E. coli and $S$. aureus and antioxidant activity were surveyed by Rasouli et al. in 2008 (18). Another research by Kaur et al. in 2010 reported that the peppermint leaf extract has antibacterial activity because of tannins and flavonoids. Further study also confirmed the antimicrobial effect in the essence of peppermint (19). Singah et al. Concluded in 2011 that peppermint extract has a greater effect on gram-positive bacteria than gramnegative bacteria; the diameter of non-growth on negative gram-negative bacteria such as $E$. coli and Klebsiella pneumonia is 12.4 and 5.1 $\mathrm{mm}$, respectively, while in the case of grampositive bacteria such as Streptococcus pyogenes and S.aureus are 17.2 and $13.1 \mathrm{~mm}$, respectively (20). In 2012, Pramila DM examined the antifungal effect of the Mentha Piperita in his research and was able to confirm it (21). Another research done in 2015 approved that previous studies have verified that thymol, carvacrol, menthol, and parasiman are the most important components in the antimicrobial activity of peppermint essence. Furthermore, it has been confirmed that as the concentration of these compounds in peppermint essence becomes greater, its antimicrobial activity will be more (22). Moreover, Zaidi et al. studied the antimicrobial activity of essential oil from Mentha piperita against 4 fungal and 11 bacterial clinical isolates; it showed the maximum activity against $S$. aureus, producing a zone of inhibition of $19.2 \pm 0.07$ $\mathrm{mm}$ (23).

\section{Conclusion}

One of the reasons for the difference MIC in different studies is the differences in the composition of the extracts. The composition of the extracts from a species can vary based on the region's geography, harvest season, plant age, growth stage, and the method of drying and extraction. In general, the plant extract has the highest antimicrobial activity during flowering or immediately after flowering. Further, the extracts obtained from different parts of a particular plant have different antimicrobial activity. Additionally, the sensitivity of different bacteria to different extracts is different. It is evident that the extract derived from the peppermint plant has antimicrobial activity against Staphylococcus aureus, Bacillus cereus, and Escherichia coli, and it can be used as alternative medicine after further investigations on laboratory animals and its side effects. 


\section{References}

1. Ahameethunisa AR, Hopper W. In vitro antimicrobial activity on clinical microbial strains and antioxidant properties of Artemisia parviflora. Ann Clin Microbiol Antimicrob. 2012;11(1):30. [DOI:10.1186/1476-0711-11-30]

2. Hancock REW. Mechanisms of action of newer antibiotics for Gram-positive pathogens. Lancet Infect Dis. 2005;5(4):209-18. [DOI:10.1016/S1473-3099(05)70051-7]

3. Uniyal SK, Singh KN, Jamwal P, Lal B. Traditional use of medicinal plants among the tribal communities of Chhota Bhangal, Western Himalaya. J Ethnobiol Ethnomed. 2006;2(1):14. [DOI:10.1186/1746-4269-2-14]

4. Shah PM. The need for new therapeutic agents: what is in the pipeline? Clin Microbiol Infect. 2005; 11:36-42.

[DOI:10.1111/j.1469$\underline{0691.2005 .01141 . x]}$

5. Rojas JJ, Ochoa VJ, Ocampo SA, Muñoz JF. Screening for antimicrobial activity of ten medicinal plants used in Colombian folkloric medicine: A possible alternative in the treatment of non-nosocomial infections. BMC Complement Altern Med. 2006;6(1):1-6. [DOI:10.1186/14726882-6-2]

6. Djeussi DE, Noumedem JAK, Seukep JA, Fankam AG, Voukeng IK, Tankeo SB, et al. Antibacterial activities of selected edible plants extracts against multidrug-resistant Gramnegative bacteria. BMC Complement Altern Med. 2013;13(1):164. [DOI: 10.1186/1472-6882-13164]

7. Sagdic O, Karahan AG, Ozcan M, Ozkan G. Note: effect of some spice extracts on bacterial inhibition. Food Sci Technol Int. 2003;9(5):353-8. [DOI:10.1177/1082013203038976]

8. Thorne RF. Classification and geography of the flowering plants. Bot Rev. 1992;58(3):225-327. [DOI: 10.1007/BF02858611]
9. Wichtl M. Herbal drugs and phytopharmaceuticals: a handbook for practice on a scientific basis. Medpharm GmbH Scientific Publishers; 2004.

10. Kumar P, Mishra S, Malik A, Satya S. Insecticidal properties of Mentha species: a review. Ind Crops Prod. 2011;34(1):802-17. [DOI:10.1016/j.indcrop.2011.02.019]

11. Sattari M, Shahbazi N, Najar Peeryeh S. An assessment of antibacterial effect of alcoholic and aquatic extracts of Eucalyptus leaves on Pseudomonas aeruginosa. Pathobiol Res. 2006;8(1):19-23.

12. Halliwell B, Gutteridge JMC. Free radicals in biology and medicine. Oxford University Press, USA;

2015.

[DOI:10.1093/acprof:oso/9780198717478.001.00

01]

13. Ames BN. Dietary carcinogens and anticarcinogens: oxygen radicals and degenerative diseases. Science (80- ). 1983;221(4617):1256-64. [DOI:10.1126/science.6351251]

14. Tylor VE. The Honest Herbal. Binghamton: Pharmaceatrial Products Press; 1993.

15. Iscan G, Kirimer R, Kurckuoglu M. Hunsu Can Baser K., Demirci F.: Screening of Mentha piperita essential oils. J Agric Food Chem. 2002;50:3943-6. [DOI:10.1021/jf011476k]

16. Dorman HJD, Koşar M, Başer KHC, Hiltunen R. Phenolic profile and antioxidant evaluation of Mentha x piperita L.(peppermint) extracts. Nat Prod Commun. 2009;4(4):1934578X0900400419. [DOI:10.1177/1934578X0900400419]

17. Moreira MR, Ponce AG, Del Valle CE, Roura SI. Inhibitory parameters of essential oils to reduce a foodborne pathogen. LWT-Food Sci Technol. 2005;38(5):565-70.

\section{[DOI:10.1016/j.lwt.2004.07.012]}

18. Rasooli I, Gachkar L, Yadegarinia D, Bagher Rezaei M, Alipoor Astaneh S. Antibacterial and antioxidative characterisation of essential oils 
from Mentha piperita and Mentha spicata grown in Iran. Acta Aliment. 2008;37(1):41-52. [DOI:10.1556/AAlim.2007.0019]

19. Kaur J, Rathinam X, Kasi M, Leng KM, Ayyalu R, Kathiresan S, et al. Preliminary investigation on the antibacterial activity of mango (Mangifera indica L: Anacardiaceae) seed kernel. Asian Pac J Trop Med. 2010;3(9):707-10. [DOI:10.1016/S1995-7645(10)60170-8]

20. Singh R, Shushni MAM, Belkheir A. Antibacterial and antioxidant activities of Mentha piperita L. Arab J Chem. 2015;8(3):322-8. [DOI:10.1016/j.arabjc.2011.01.019]

21. Pramila DM, Xavier R, Marimuthu K, Kathiresan S, Khoo ML, Senthilkumar M, et al. Phytochemical analysis and antimicrobial potential of methanolic leaf extract of peppermint (Mentha piperita: Lamiaceae). J Med Plants Res. 2012;6(2):331-5. [DOI:10.5897/JMPR11.1232]
22. Beuchat LR, Golden DA. Antimicrobials occurring naturally in foods. Food Technol. 1989;

23. Zaidi S, Dahiya P. In vitro antimicrobial activity, phytochemical analysis and total phenolic content of essential oil from Mentha spicata and Mentha piperita. Int Food Res J. 2015;22(6):2440.

\section{How to cite:}

Mahmoudi S, Nasiri R, Jafari Sales A. In-vitro antibacterial effects of methanolic extract of peppermint (Mentha Piperita Lamiaceae) on standard Staphylococcus aureus, Bacillus cereus, Escherichia coli and Pseudomonas aeruginosa strain. Jorjani Biomedicine Journal. 2019; 7(4): 4-10. 